\title{
Anal and cervical cytologic abnormalities among HIV-infected women in the era of HAART EM Kojic*1, C Wang ${ }^{1}$, L Boardman ${ }^{2}$ and S Cu-Uvin ${ }^{1}$
}

Address: ${ }^{1}$ Department of Infectious Diseases, The Miriam Hospital/Brown University, Providence, Rhode Island, USA and ${ }^{2}$ Women and Infant's Hospital, Providence Rhode Island, USA

* Corresponding author

from I I th International Conference on Malignancies in AIDS and Other Acquired Immunodeficiencies (ICMAOI): Basic, Epidemiologic, and Clinical Research

Bethesda, MD, USA. 6-7 October 2008

Published: 17 June 2009

Infectious Agents and Cancer 2009, 4(Suppl 2):P25 doi:10.1 186/1750-9378-4-S2-P25

This abstract is available from: http://www.infectagentscancer.com/content/4/S2/P25

(C) 2009 Kojic et al; licensee BioMed Central Ltd.

\section{Background}

Cervical human papillomavirus (HPV) infections and abnormal cervical cytology are more prevalent and persistent in HIV-infected compared with uninfected women. Less is known about anal HPV infections and abnormal anal cytology in women and whether findings in the cervix correlate with findings in the anus. The correlation between cytology and histology in the anal area has been even less studied. Here we evaluate the prevalence of anal and cervical cytologic abnormalities and evaluate if the abnormal cytology is associated with abnormal histology as evaluated by biopsies.

\section{Methods}

This is a cross sectional study of HIV-infected patients receiving care at the Miriam Hospital, Providence, Rhode Island. All women that were due for the annual cervical Pap smear were offered to participate in the study. Each participant had cervical and anal swabs for cytopathologic examination (Pap tests) and cervical and anal cytobrush and swab obtained for HPV typing. Any abnormal cytology was followed up with a colposcopy and anoscopy respectively and biopsies obtained.

\section{Results}

Cervical and anal cytology results were available for 80 women. Mean age was 43 years (range 24-60), and race was 50 percent white, 34 percent African American, 14 percent Hispanic, 10 percent other. The median CD4 count was 564 cells $/ \mathrm{mm}^{3}$ (range 44 to 1470 cells $/ \mathrm{mm}^{3}$ ).
Fourteen women $(18 \%)$ were antiretroviral naïve, 64 women $(80 \%)$ were taking antiretroviral therapy, and two had an unknown medication history. The mean HIV viral load was 18,318 copies $/ \mathrm{mL}, 56$ percent of the women had an undetectable HIV viral load. The prevalence of an abnormal cytology (atypical squamous cells of undetermined significance [ASCUS], low- or high-grade squamous intraepithelial lesions [SIL]) in anus or cervix was 40 percent ( 32 out of 80 women); 22 percent in the anus, and 26 percent in the cervix (not statistically significant). Eight out of 32 women (25\%) had an abnormal cytology at both anatomical areas, 10 of $32(31 \%)$ women had an abnormal anal cytology only, and 14 of 32 (44\%) women had an abnormal cervical cytology only. Up to date, 5 out of 18 women with an abnormal anal cytology have undergone anoscopy with biopsy results that were all normal. Nine women out of the 22 women that had an abnormal cervical Pap smear have had a colposcopy with biopsy and only one cervical intraepithelial neoplasia II.

\section{Conclusion}

Preliminary results in this cohort of HIV-infected women with a high mean CD4 cell count shows that there is a high prevalence of abnormal cytology and it is similar in both cervix and anus. The majority of women had abnormal cytology in either anus or cervix but not both. A limited number of women have undergone histology sampling, and all but one had normal results. Additional biopsies have been scheduled and HPV typing is being analyzed. 